\title{
Effects of projected changes in tropical cyclone frequency on sea turtles
}

\author{
M. M. P. B. Fuentes ${ }^{1,3, *}$, D. Abbs ${ }^{2}$ \\ ${ }^{1}$ School of Earth and Environmental Sciences, James Cook University, Townsville, Queensland 4811, Australia \\ ${ }^{2}$ Centre for Australian Weather and Climate Research, Aspendale, Victoria 3195, Australia \\ ${ }^{3}$ Present address: Centre of Excellence for Coral Reef Studies, James Cook University, Townsville, Queensland 4811, Australia
}

\begin{abstract}
Tropical cyclones are amongst the world's most destructive natural hazards and can negatively affect sea turtles by disturbing their foraging and nesting habitats, increasing localised mortality of their eggs, and potentially skewing hatchling sex ratios towards females. Cyclonic frequency, intensity, distribution and seasonality are predicted to alter with climate change. This will influence both the effects of cyclones on the nesting grounds and reproductive output of sea turtles and the frequency with which these nesting grounds are hit by cyclones. However, only a few studies have investigated how future cyclonic activity will affect turtle populations. Studies conducted to date have concentrated on how projected intensification of cyclonic activity will affect sea turtles and have found that intensification of cyclones will reduce hatching success at sea turtle nesting grounds. No study to date has, however, considered or investigated how the predicted changes in cyclone frequency and distribution may affect sea turtle populations. Here, we used climate change models and turtle life history information to predict how projected changes in the frequency of cyclones will affect 4 sea turtle species: green turtle Chelonia mydas, flatback turtle Natator depresus, hawksbill turtle Eretmochelys imbricata and loggerhead turtle Caretta caretta, nesting on the eastern Australian (Queensland) coast. To account for known variability in model projections of cyclonic activity, we used 11 regional climate model simulations for an A2 greenhouse gas emission scenario for conditions predicted for 2055 and 2090. The model projections indicated a tendency towards a reduction in cyclonic activity at the studied nesting grounds in the future and, thus, a decrease in the effects on sea turtle nesting along the Queensland coast.
\end{abstract}

KEY WORDS: Climate change - Tropical cyclones $\cdot$ Sea turtles $\cdot$ Nesting grounds $\cdot$ Green turtle · Loggerhead turtle $\cdot$ Flatback turtle $\cdot$ Hawksbill turtle

\section{INTRODUCTION}

Many of the world's sea turtle populations have experienced drastic reductions due to overexploitation, pollution, anthropogenic disturbances, habitat degradation and predation (see Johannes \& Macfarlane 1991, Harris et al. 2000, Lutcavage et al. 2003, Moore et al. 2009). Even though some populations of sea turtles have started to recover (Chaloupka et al. 2008), sea turtles are still recognized as species of conservation concern and are protected under various conventions, legislations and treaties. There has been recent concern that climate change will cause further declines in sea turtle populations and exacerbate this status (Fuentes et al. 2009a, 2010a, Hawkes et al. 2009, Poloczanska et al. 2009). This is because sea turtles have life cycle history (e.g. slow growth rate, late maturity) and physiology (e.g. temperature-dependent sex determination) traits that make them extremely sensitive to climate change (Spotila \& Standora 1985, Janzen 1994, Davenport 1997, Hawkes et al. 2009). Arguably, the more detectable effects of climate change on sea turtles will occur during their terrestrial reproductive phase (egg laying, egg incubation and hatchling success) since there are clear and relatively straightforward effects of warmer temperature, sea- 
level rise and cyclonic activity on sea turtle nesting sites and reproductive output (Hawkes et al. 2009, Witt et al. 2010).

Considering the potential effects of climate change on sea turtles, studies have begun to predict how specific climatic processes will affect sea turtles' terrestrial reproductive phase (Hawkes et al. 2009, Poloczanska et al. 2009). Up until 2009, most of the studies focused on the potential effects of warmer temperatures (Hays et al. 1999, 2003, Glen \& Mrosovsky 2004, Hawkes et al. 2007, Fuentes et al. 2009b, 2010a,b) or sea-level rise (Fish et al. 2005, 2008, Baker et al. 2006, Fuentes et al. 2010c). A warmer temperature poses serious threats to sea turtle populations since sex determination and hatching success are influenced by nest temperature. Warmer sand temperatures may skew sea turtle population sex ratios towards predominantly females and decrease hatching success, as eggs may be consistently exposed to temperatures that exceed thermal mortality thresholds (Yntema \& Mrosovsky 1980, Spotila \& Standora 1985, Ackerman 1997, Davenport 1997, Matsuzawa et al. 2002, Carthy et al. 2003). Sealevel rise can cause loss and alteration of nesting beaches and increase egg mortality (Fish et al. 2005, 2008, Baker et al. 2006, Mazaris et al. 2009, Fuentes et al. 2010c).

Cyclonic activity can have further impacts on sea turtles' reproductive output. Cyclones can affect sea turtles in the long term, over several generations, by removing and altering their nesting habitat (i.e. through beach erosion) and in the short-term incubation period (6 to $8 \mathrm{wk}$ ), by increasing localized (temporal and spatial) mortality of their eggs (Milton et al. 1994, Martin 1996, Pike \& Stiner 2007). In addition, because both incubation duration and gender of sea turtle hatchlings is affected by the sand temperature during incubation (Miller \& Limpus 1981, Morreale et al. 1982), cooling from increased rainfall and cloud cover during cyclonic events can play a role in influencing phenotype and sex ratios of hatchlings from eggs deposited on beaches (Reed 1980, Godfrey et al. 1996, Houghton et al. 2007). A further and less frequently documented effect of cyclones on turtles is the increased probability of stranding events (see Limpus \& Reed 1985).

Cyclonic frequency, intensity, distribution and seasonality are predicted to alter with climate change (Walsh \& Ryan 2000, Webster et al. 2005, Abbs et al. 2007, Leslie et al. 2007, Kuleshov et al. 2008). Thus, the effects of cyclones on sea turtle nesting grounds and reproductive output and the frequency with which nesting grounds are hit by cyclones are likely to change (Van Houtan \& Bass 2007, Munday et al. 2008). However, there have been only a few studies that have investigated how future cyclonic activity will affect tur- tle populations (e.g. Pike \& Stiner 2007, Van Houtan \& Bass 2007). These studies have concentrated on how projected intensification of cyclonic activity will affect sea turtles and have found that intensification of cyclones will reduce hatching success at sea turtle nesting grounds (Van Houtan \& Bass 2007). However, no study to date has considered or investigated how the predicted changes in cyclone frequency may affect sea turtle populations.

To address this, we investigated the effects of the projected change in the frequency of cyclones by 2055 and 2090 at nesting grounds used by 4 sea turtle species: green turtle Chelonia mydas; flatback turtle Natator depresus; hawksbill turtle Eretmochelys imbricata; and loggerhead turtle Caretta caretta, across a large geographic region - the eastern Australian coast. To investigate this we used outputs from a total of 11 downscaled regional climate model simulations for an A2 greenhouse gas emission scenario. Further, we compared the nesting phenology of each sea turtle population with the temporal scale of cyclonic activity at the study region to investigate whether the timing of sea turtle nesting affects their vulnerability to cyclonic activity.

\section{METHODS}

Study region. This study focused on the eastern Queensland coast and adjacent islands of the Great Barrier Reef World Heritage Area and Torres Strait (Fig. 1). This region contains 7 globally significant populations of sea turtles: (1) the southern Great Barrier Reef (sGBR), (2) the Coral Sea (CS) and (3) the northern Great Barrier Reef (nGBR) green turtle populations (the latter is the largest green turtle population in the world, Limpus et al. 2003), (4) the Gulf of Carpentaria (GC) flatback, (5) the eastern Australian (EA) flatback populations (flatback populations are endemic to Australia), (6) the hawksbill population (one of the largest nesting populations of hawksbill turtles in the world, Dobbs et al. 1999) and (7) the eastern Australian (EA) loggerhead population (Fig. 1).

Nesting data. Information on the distribution and timing of nesting for each turtle population was gathered from published material (Limpus 1971, Limpus et al. 1993, 2003, Dobbs et al. 1999, Limpus \& Miller 2000, Harvey et al. 2005) and used to generate a GIS-based layer of nesting locations and times. For the purpose of the present study, minor rookeries $(<10$ nesting turtles $\mathrm{yr}^{-1}$ ) are not represented in the nesting layers.

Historical cyclone data. Temporal information on cyclone activity in the study region was obtained from the Australian Bureau of Meteorology for years from 1961 to 2000. Data produced before the 1960 to 1961 seasons 


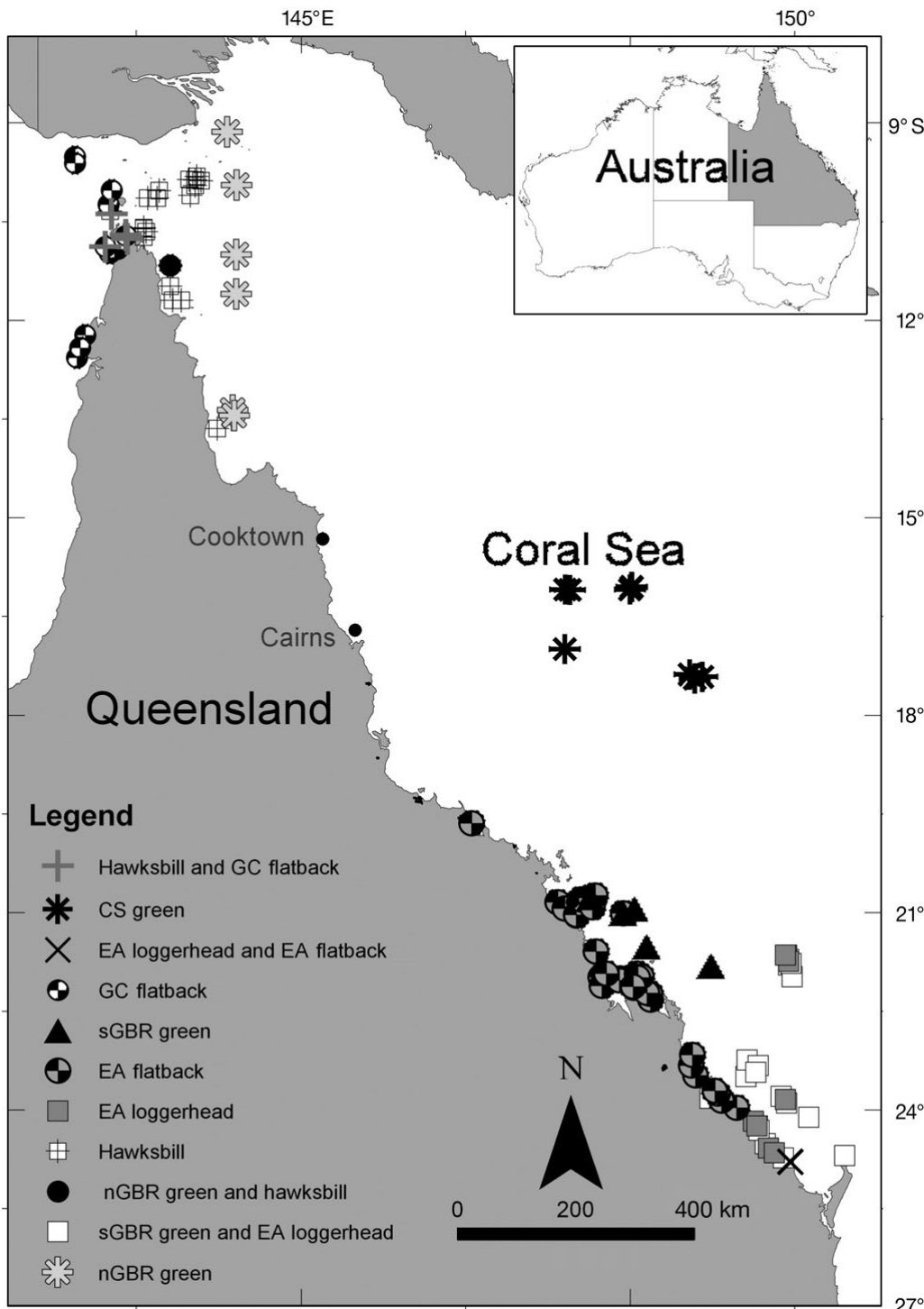

Fig. 1. Eastern Queensland, Australia, showing the locations of the 7 populations of sea turtles nesting in this region. GC: Gulf of Carpentaria; CS: Coral Sea; EA: eastern Australia; sGBR: southern Great Barrier Reef; nGBR: northern Great Barrier Reef were not used due to lack of observations before this time (Holland 1981).

Regional climate models. Climate simulations were generated using the Commonwealth Scientific and Industrial Research Organisation (CSIRO) Conformal-Cubic Atmospheric Model (CCAM) (McGregor 2005, McGregor \& Dix 2008). As CCAMs are computationally expensive to run, results for one emission scenario (A2) only were modeled. The A2 scenario describes a very heterogeneous world, with a continuously increasing human population. Economic development is primarily regionally oriented and per capita economic growth and technological change is more fragmented and slower than for other scenarios (IPCC 2007). CCAM is a global climate model that uses a stretched grid, formed by projecting the panels of a cube onto the surface of the Earth. The cube is then stretched so that the area of interest (Australia) is simulated at a high resolution (approximately $65 \mathrm{~km}$ grid), with resolution then decreasing with distance from Australia.

The CCAM simulations were based on the outputs from general circulation models (GCM) (Table 1) sourced from the Intergovernmental Panel on Climate Change (IPCC) CMIP3 archive and were downscaled using 2 different methods. (1) The bias-corrected sea surface temperature (SST) method forced the model with biascorrected sea surface temperatures only. This method has the advantage that the cold sea surface temperature bias in the central equatorial Pacific, which is a characteristic of many GCMs, is not included in these simulations and, thus, the CCAM simulations develop large-scale circula-

Table 1. Conformal-cubic atmospheric host models and downscaling method used to investigate cyclonic activity for 2055 and 2090 at nesting sites used by sea turtle populations nesting on the eastern Queensland coast. SST: sea surface temperature

\begin{tabular}{|lll|}
\hline Host model & Institution & Downscaling method \\
\hline ECHAM5 & Max Planck Institution & Bias-corrected SST (SST) \\
GFDL 2.0 & NOAA Geophysical Fluid Dynamics Laboratory & Bias-corrected SST (SST) \\
GFDL 2.1 & NOAA Geophysical Fluid Dynamics Laboratory & Bias-corrected SST (SST) \\
MIROC 3.2 - medres & CCSR/NIES/FRCGC, Japan & Bias-corrected SST (SST) \\
Mk3.5 - A2 - B35 & Australian Commonwealth Scientific and Research Organization & Bias-corrected SST (SST) \\
UK HADCM3 & Hadley Centre in the UK & Bias-corrected SST (SST) \\
ECHAM5 & Max Planck Institution & Large-scale forcing (forced) \\
GFDL 2.1 & NOAA Geophysical Fluid Dynamics Laboratory & Large-scale forcing (forced) \\
MIROC 3.2 - medres & CCSR/NIES/FRCGC, Japan & Large-scale forcing (forced) \\
Mk3.5 - A2 - B35 & Australian Commonwealth Scientific and Research Organization & Large-scale forcing (forced) \\
Mk3.0_A2_M20th & Australian Commonwealth Scientific and Research Organization & Large-scale forcing (forced) \\
\hline
\end{tabular}


tions that are unaffected by these biases. This technique allows long (140 yr) simulations to be conducted; however, there are indications that this technique does not account for the intermodel variability seen between the host models (Abbs 2009). (2) The largescale forcing (forced) method nudges the CCAM solution towards the large-scale winds, temperatures and pressures from the host GCM. Both simulations use 'uncorrected' SSTs from the host model, so the resulting simulations may develop large-scale circulations that are a response to the SST biases of the host model. Simulations with forced nudging can only use $20 \mathrm{yr}$ time slice experiments for 2046 to 2065 and 2081 to 2100 , due to the lack of atmospheric forcing data for other periods. However, these simulations have the advantage that they account for the intermodel variability seen between the host models (Abbs 2009).

Tropical cyclone-like vortices (TCLVs) were detected from daily outputs from the CCAM. The TCLV detection and tracking scheme used here is modified from that of Nguyen \& Walsh (2001). The scheme searches for low pressure systems that have the physical characteristics of tropical cyclones (e.g. high wind speeds, rotation of winds and a warm core). These TCLVs are 'tracked' in subsequent outputs and the results collated to yield a population of modeled TCLVs that are subsequently analysed to identify possible changes in their frequency.

Projected changes in TCLV frequency were calculated for future climates representative of 2055 and 2090 using TCLV detections for 2046 to 2065 and 2081 to 2100 , respectively. All changes are relative to average annual simulated cyclone frequency representative of the 1961 to 2000 climate. To quantify the climatological accuracy of each of the 11 simulations we created a scale factor that compares modeled simulation of past TC activity (1961 to 2000) with observations of past TC activity. For this, we simulated past TC activity (1961 to 2000) using each of the 11 models and then compared the results with the observed cyclonic activity acquired from the Australian Bureau of Meteorology (see 'Historical cyclone data'). A scale factor of 1 is ideal, meaning that the model predicted accurately the observed frequency of cyclones in the past; a scale value of 0.5 overrepresents past cyclone occurrence by 2 times and a scale value of 2 underrepresents past cyclone occurrence by one-half.

\section{RESULTS}

\section{Historical cyclonic activity and nesting phenology}

Sea turtles nesting on the eastern Queensland coast have historically (1961 to 2000) been hit by a low number of cyclones a year (average, 0.125 to $1.75 \pm 0.32$ [mean $\pm \mathrm{SE}$ ] cyclones $\mathrm{yr}^{-1}$ ). The frequency of cyclone hits at each nesting ground varied among the different sea turtle populations as a result of the spatial distribution of their nesting grounds. Populations nesting on the southern and eastern Queensland coasts and on the Coral Sea, such as the sGBR and CS green turtle population, the EA flatback turtle population and the EA loggerhead turtle population, generally had a higher frequency of cyclonic activity $(0.73 \pm 0.035,1.64 \pm 0.2$,

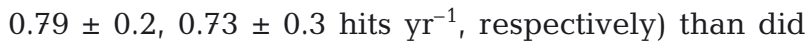
populations with nesting grounds in the Torres Strait region and the northern and eastern Queensland coasts, such as the nGBR green turtle population and the hawksbill turtle population $(0.48 \pm 0.08$ and $0.46 \pm$ 0.04 hits $\mathrm{yr}^{-1}$, respectively) (Fig. 2). No pattern was found in relation to the average intensity of cyclones at nesting grounds used by the various sea turtle populations. The CS green turtle population was hit on average by more intense cyclones (average intensity of 2.1) and the EA flatback turtle population was hit on average by cyclones with lower intensity (average intensity of 1.66).

Historically (1961 to 2000) cyclonic activity has occurred between November and May in the study region, with peak cyclone activity occurring during February $\left(30.8 \%\right.$ of cyclones, 1.2 hits $\left.\mathrm{yr}^{-1}\right)$ and January (23.8\% of cyclones, 0.9 hits $\mathrm{yr}^{-1}$ ) (Fig. 3).

Peak nesting for the 3 green turtle populations (December to January) and the hawksbill population (January to February) coincides with peak cyclone activity (January to February). Peak nesting for the loggerhead and EA flatback turtle populations occurs in December (before the peak cyclone season), but a high proportion of their eggs are still incubating during the peak of the cyclone season (Fig. 3). In contrast, the peak of the nesting season (July to September) for the GC flatback turtle population occurs outside the cyclone season.

\section{Regional climate models}

According to the scale factor developed for testing historical empirical data, there is no 'best' model for the study region, but some model simulations are better than others for the different populations of sea turtles (scale factor ranged from 0.7 to 38 , where for a scale factor of 1 , the model accurately predicts observed cyclonic activity; for a scale factor of 0.5 , the model overrepresents cyclone occurrence by 2 times; and for a scale factor of 2 , the model underrepresents cyclone occurrence by one-half) . Overall, the downscaled NOAA Geophysical Fluid Dynamics Laboratory (GFDL) 2.1 models (both the SST and forced) best simulated the observed cyclonic activity (average scale factors of 1.2 


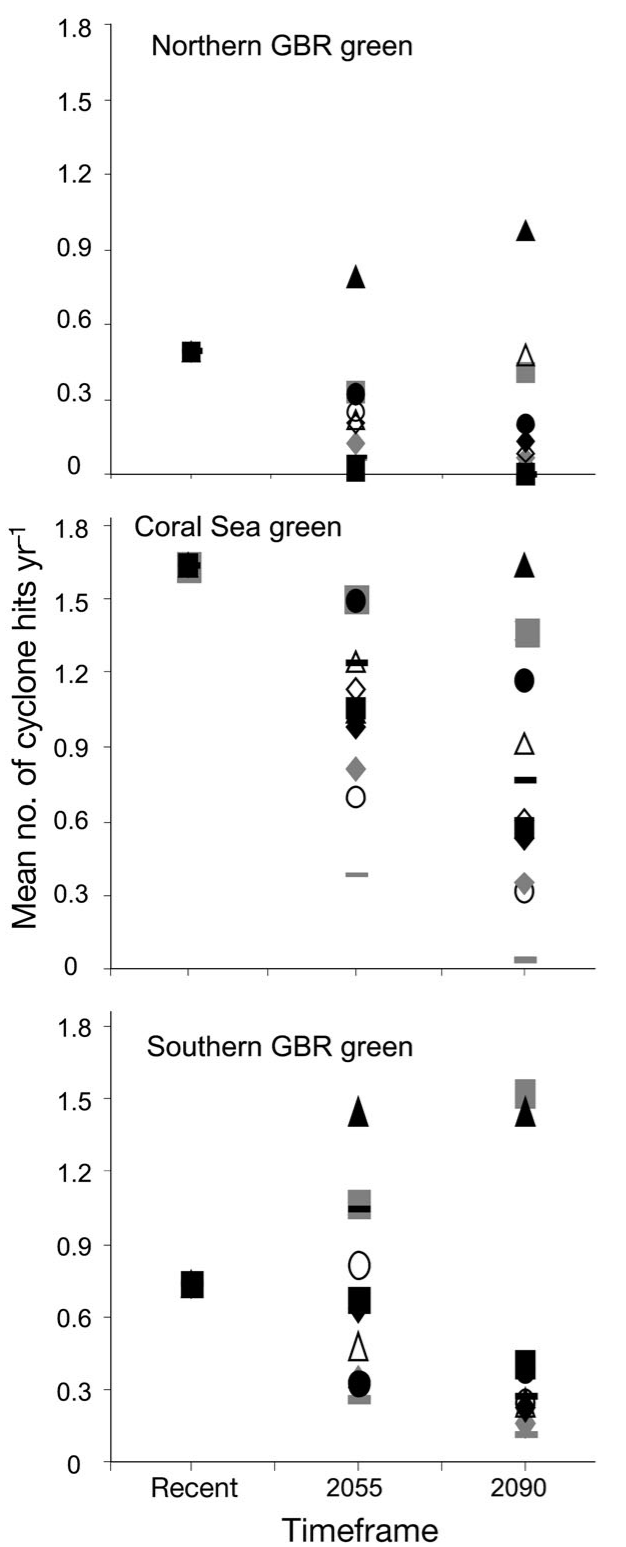

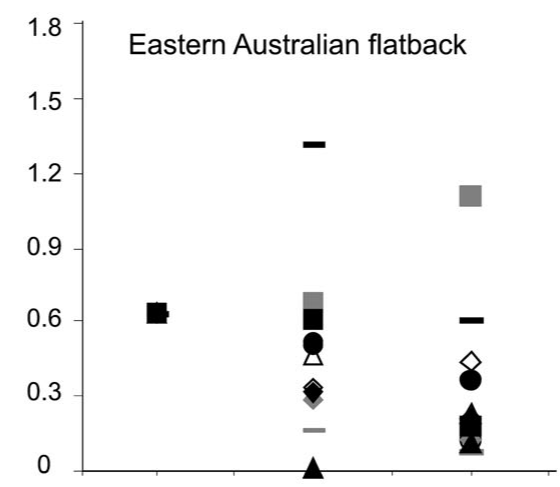
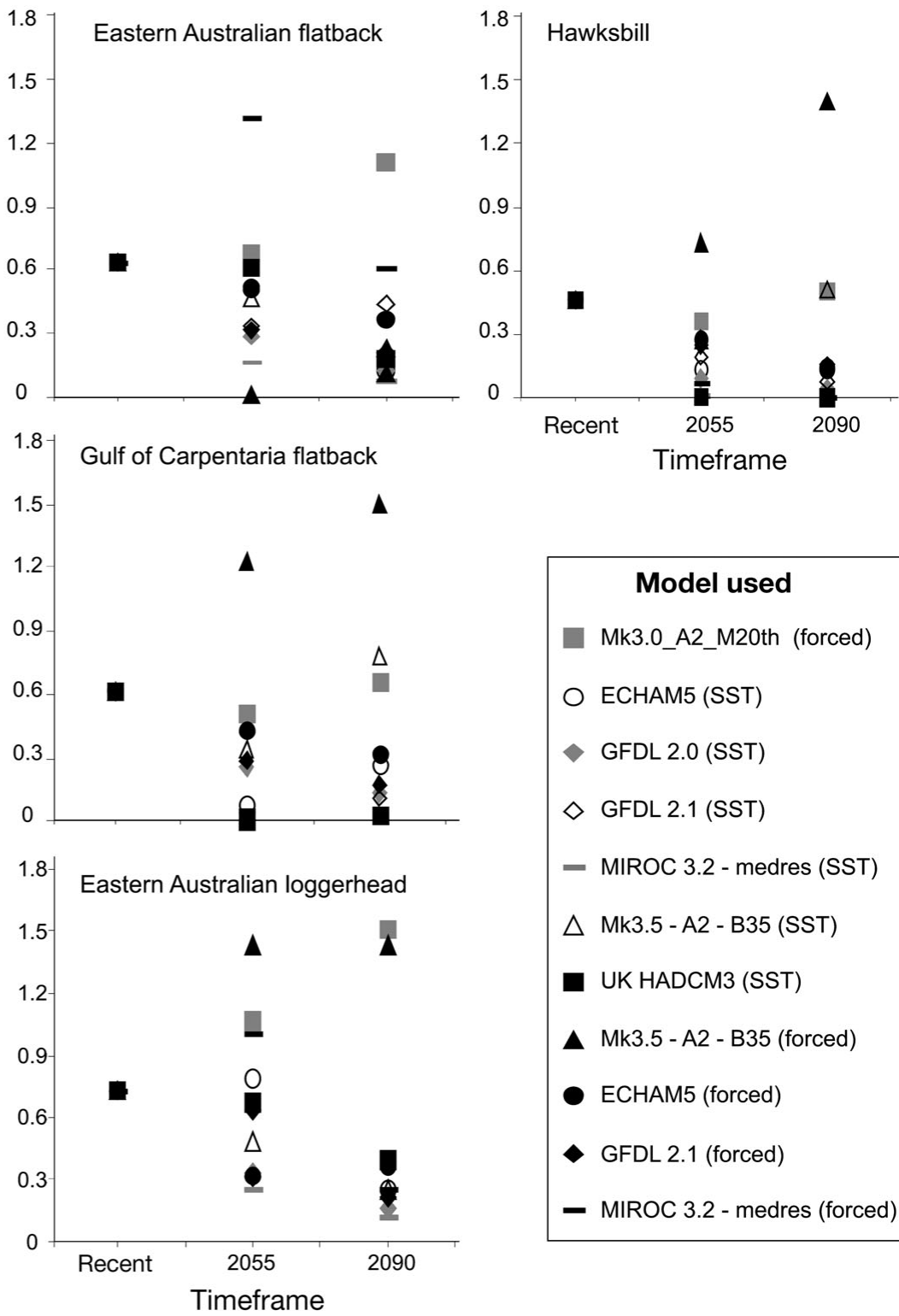

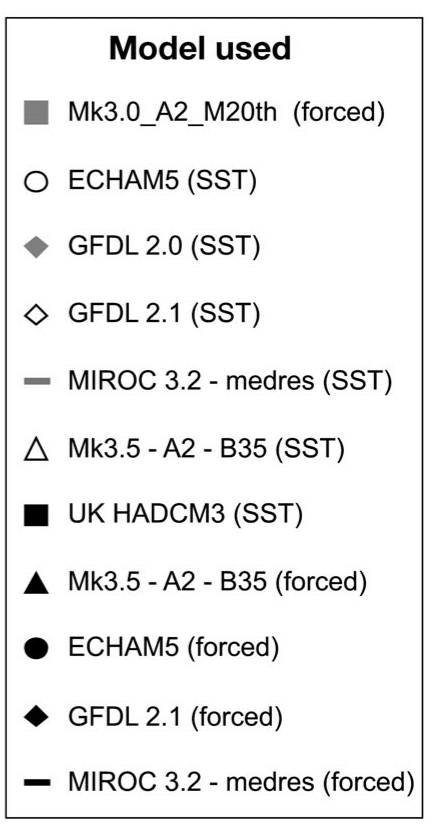

Fig. 2. Recent (1961 to 2000) and projected (for 2055 and 2090) mean annual tropical cyclone frequency hit for each sea turtle population nesting on the eastern Queensland coast. GBR: Great Barrier Reef. For further details of the models see Tables 1 to 3

and 0.94, respectively). The forced Mk3.5 simulations generated the worst results for the study region and usually underrepresented the observed cyclonic activity at all of the nesting grounds (average scale factor of 18.38) (Table 2). Thus, the results from the forced Mk3.5 simulations are not presented in this paper.

\section{Projected changes in the frequency of cyclones}

There was great variability in cyclone frequency between the various climate models in the regional predictions for both 2055 and 2090. Nevertheless, the model simulations that best represent the observed climate for 1961 to 2000 (i.e. models with scale =1, see Table 2) indicate a strong tendency for future decrease in cyclone numbers per year at the nesting grounds used by the 7 sea turtle populations (Tables $2 \& 3$, Fig. 2). Based on the simulations from the models that best represent cyclonic activity for each turtle population, the frequency of cyclones affecting the study region will decrease by 18 to $58 \%$ and 47 to $82 \%$ by 2055 and 2090, respectively. The EA loggerhead turtle population and the nGBR and sGBR green turtle populations will probably experience the biggest reduction in cyclonic frequency at their nesting grounds, with the 


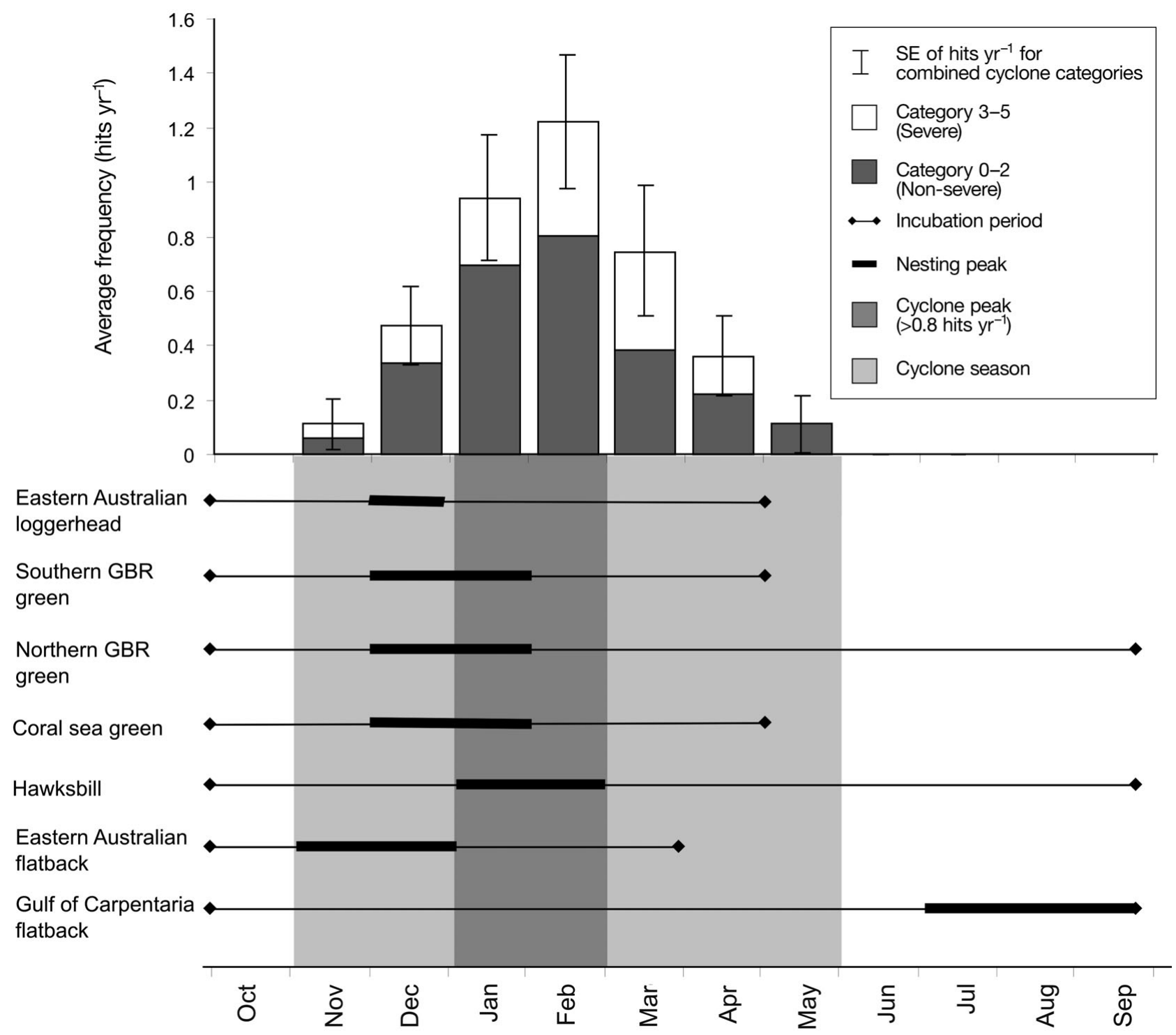

Fig. 3. Nesting phenology of each sea turtle population compared with average (1961-2000) monthly tropical cyclone hits in the study region. GBR: Great Barrier Reef

mean annual cyclone hit decreasing from $0.73,0.48$,

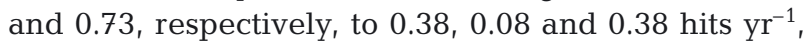
respectively, by 2090 (Fig. 2).

\section{DISCUSSION}

Global warming is expected to alter the frequency, intensity, distribution and timing of cyclones (Walsh \& Ryan 2000, Webster et al. 2005, Abbs et al. 2007, Leslie et al. 2007, Kuleshov et al. 2008). These changes will probably alter the effect of cyclones on various habitats and biodiversity as well as the exposure (frequency hit) of these habitats to cyclones (Van Houtan \& Bass 2007, Munday et al. 2008). Indeed, we found that the number of cyclones that will disturb the nesting grounds used by the 7 populations of sea turtles in the eastern Queensland coast is projected to decrease. A reduction in the frequency of cyclonic activity, as predicted here, will reduce the frequency of nest disturbance and lengthen recovery times of nesting grounds after a cyclonic episode. An intensification of cyclones, as predicted by other studies (e.g. Knutson \& Tuleya 2004, Kuleshov et al. 2008), will probably cause a reduction in the number of hatchlings at nesting grounds, as nest inundation is positively related to cyclone intensity (Pike \& Stiner 2007, Van Houtan \& Bass 2007). Further, if earlier-than-usual tropical cyclone formation and seasons occur in the Australian region as a result of projected warmer SST (as suggested by Nicholls 1984), 
Table 2. Scale factor developed to investigate the accuracy of each conformal-cubic atmospheric host model simulation. 1: model accurately predicts observed cyclonic activity; 0.5 : model over represents cyclone occurrence by $200 \%$; and 2: model underrepresents cyclone occurrence by $50 \%$. Values in bold represent the model results that most accurately simulate cyclonic activity for each nesting population and those in italics represent those with the most underestimated cyclone occurrence (>2). No models overestimated cyclone occurrence by 2 or more $(<0.5)$. nGBR: northern Great Barrier Reef; CS: Coral Sea; sGBR: southern Great Barrier Reef; GC: Gulf of Carpentaria; EA: eastern Australian; SST: sea surface temperature

\begin{tabular}{|c|c|c|c|c|c|c|c|}
\hline \multirow{2}{*}{ Model } & \multirow[b]{2}{*}{$\begin{array}{l}\text { nGBR } \\
\text { green }\end{array}$} & \multirow[b]{2}{*}{$\begin{array}{c}\text { CS } \\
\text { green }\end{array}$} & \multirow{2}{*}{ sGBR } & \multicolumn{2}{|c|}{ rtle population } & \multirow[b]{2}{*}{$\begin{array}{c}\text { EA } \\
\text { loggerhead }\end{array}$} & \multirow[b]{2}{*}{ Hawksbill } \\
\hline & & & & $\begin{array}{c}\text { GC } \\
\text { flatback }\end{array}$ & $\begin{array}{c}\text { EA } \\
\text { flatback }\end{array}$ & & \\
\hline Mk3.0_A2_M20th (forced) & 0.8 & 1.3 & 1.9 & 1.4 & 1.4 & 1.9 & 0.8 \\
\hline ECHAM5 (SST) & 3.2 & 1.2 & 1.7 & 5.3 & 1.0 & 1.7 & 4.6 \\
\hline GFDL 2.0 (SST) & 1.1 & 1.1 & 1.2 & 1.7 & 0.9 & 1.2 & 1.3 \\
\hline GFDL 2.1 (SST) & 1.0 & 1.0 & 1.0 & 1.8 & 1.1 & 1.0 & 1.5 \\
\hline MIROC 3.2 - medres (SST) & 2.4 & 1.6 & 1.4 & 4.9 & 1.2 & 1.4 & 4.4 \\
\hline $\mathrm{Mk} 3.5-\mathrm{A} 2-\mathrm{B} 35$ (SST) & 2.1 & 1.5 & 1.7 & 4.5 & 1.3 & 1.7 & 2.9 \\
\hline UK HADCM3 (SST) & 2.9 & 1.4 & 1.7 & 3.3 & 1.1 & 1.7 & 3.6 \\
\hline Mk3.5 - A2 - B35 (forced) & 1.7 & 8.2 & 38.0 & 14.0 & 20.9 & 37.0 & 8.9 \\
\hline ECHAM5 (forced) & 9.3 & 1.8 & 1.3 & 1.5 & 1.5 & 1.3 & 1.0 \\
\hline GFDL 2.1 (forced) & 0.9 & 0.9 & 1.1 & 1.1 & 0.7 & 1.1 & 0.8 \\
\hline MIROC 3.2 - medres (forced) & 0.7 & 4.9 & 5.7 & 1.8 & 5.3 & 5.6 & 1.4 \\
\hline
\end{tabular}

Table 3. Percentage of predicted changes in cyclone frequency for each sea turtle population under different simulation models for the years 2055 and 2090. Positive numbers indicate a positive increase in frequency of cyclones; negative numbers indicate a decrease in cyclonic activity. For comparison, the observed historical frequency of cyclone hits per year for each sea turtle population is indicated in parentheses below each sea turtle population. Values in bold represent the most accurate simulations and those in italics represent the least accurate simulations. nGBR: northern Great Barrier Reef; CS: Coral Sea; sGBR: southern Great Barrier Reef; GC: Gulf of Carpentaria; EA: eastern Australian

\begin{tabular}{|c|c|c|c|c|c|c|c|c|c|c|c|c|c|c|}
\hline \multirow{3}{*}{$\begin{array}{l}\text { Model } \\
\text { Year }\end{array}$} & \multirow{2}{*}{\multicolumn{2}{|c|}{$\begin{array}{l}\text { nGBR } \\
\text { green } \\
(0.48)\end{array}$}} & \multirow{2}{*}{\multicolumn{2}{|c|}{$\begin{array}{l}\text { CS } \\
\text { green } \\
(1.64)\end{array}$}} & \multirow{2}{*}{\multicolumn{2}{|c|}{$\begin{array}{l}\text { sGBR } \\
\text { green } \\
(0.73)\end{array}$}} & \multirow{2}{*}{\multicolumn{2}{|c|}{$\begin{array}{c}\text { Sea turtle popula } \\
\text { GC } \\
\text { flatback } \\
(0.61)\end{array}$}} & \multirow{2}{*}{\multicolumn{2}{|c|}{$\begin{array}{c}\text { EA } \\
\text { flatback } \\
(0.63)\end{array}$}} & \multirow{2}{*}{\multicolumn{2}{|c|}{$\begin{array}{c}\text { EA } \\
\text { loggerhead } \\
(0.73)\end{array}$}} & \multirow{2}{*}{\multicolumn{2}{|c|}{$\begin{array}{c}\text { Hawksbill } \\
\qquad(0.46)\end{array}$}} \\
\hline & & & & & & & & & & & & & & \\
\hline & 2055 & 2090 & 2055 & 2090 & 2055 & 2090 & 2055 & 2090 & 2055 & 2090 & 2055 & 2090 & 2055 & 2090 \\
\hline $\begin{array}{l}\text { Mk3.0_A2_M20th } \\
\text { (forced) }\end{array}$ & -25.3 & -6.9 & -8.1 & -16.6 & 44.7 & 107.6 & -17.6 & 5.5 & 7.1 & 75.3 & 45.9 & 107.2 & -21.5 & 7.6 \\
\hline ECHAM5 (SST) & -49.2 & -96.4 & -57.4 & -80.7 & 10.4 & -66.3 & -87.6 & -57.2 & -18.1 & -80.3 & 8.4 & -65.9 & -72.0 & -70.9 \\
\hline GFDL 2.0 (SST) & -74.9 & -87.2 & -50.8 & -78.5 & -54.4 & -79.4 & -57.8 & -78.0 & -54.8 & -80.0 & -54.9 & -78.9 & -79.8 & -89.2 \\
\hline GFDL 2.1 (SST) & -57.9 & -82.1 & -31.1 & -63.1 & -58.4 & -47.7 & -53.8 & -81.8 & -47.7 & -30.8 & -58.1 & -47.5 & -58.1 & -82.7 \\
\hline $\begin{array}{l}\text { MIROC } 3.2- \\
\text { medres (SST) }\end{array}$ & -87.2 & -100.0 & -76.5 & -98.0 & -65.4 & -85.0 & -92.2 & -100.0 & -74.7 & -87.3 & -65.9 & -84.8 & -98.2 & -100.0 \\
\hline $\begin{array}{l}\text { Mk3.5 - A2 - B35 } \\
\text { (SST) }\end{array}$ & -55.9 & -2.6 & -24.4 & -44.5 & -34.8 & -66.3 & -44.8 & 25.7 & -26.7 & -63.2 & -33.6 & -65.9 & -40.8 & 9.4 \\
\hline $\begin{array}{l}\text { UK HADCM3 } \\
\text { (SST) }\end{array}$ & -96.9 & -100.0 & -35.4 & -65.1 & -9.1 & -45.5 & -100.0 & -96.2 & -3.9 & -71.4 & -8.7 & -45.3 & -99.1 & -100.0 \\
\hline $\begin{array}{l}\text { Mk3.5 - A2 - B35 } \\
\text { (forced) }\end{array}$ & 61.0 & 99.5 & -36.4 & -0.2 & 96.8 & 96.8 & 97.7 & 141.6 & -98.2 & -83.0 & 96.0 & 96.0 & 56.5 & 201.6 \\
\hline ECHAM5 (forced) & -33.8 & -57.9 & -9.0 & -28.9 & -56.3 & -49.0 & -30.3 & -49.4 & -19.8 & -41.9 & -56.3 & -49.8 & -41.3 & -69.5 \\
\hline GFDL 2.1 (forced) & -34.4 & -72.8 & -40.3 & -68.0 & -13.6 & -70.4 & -52.9 & -72.0 & -49.5 & -67.5 & -12.9 & -70.8 & -46.0 & -65.5 \\
\hline $\begin{array}{l}\text { MIROC } 3.2 \text { - } \\
\text { medres (forced) }\end{array}$ & -85.1 & -100.0 & -24.0 & -53.1 & 41.3 & -64.2 & -91.9 & -95.1 & 108.0 & -4.9 & 37.3 & -66.2 & -85.4 & -100.0 \\
\hline
\end{tabular}

populations of sea turtles that nest earlier in the year, such as the EA flatback turtle, will probably be more affected.

Similarly, the impact and disturbance that sea turtle nesting grounds will experience in the future as a result of cyclones will also be affected by any change in the behaviour of sea turtle populations as an adapta- tion strategy to climate change. For example, if turtles nesting on the eastern Queensland coast start to nest earlier as a result of warmer SST, a behavior which has been observed for loggerhead turtles in Florida (Weishampel et al. 2004, Pike et al. 2006), the level of disturbance that they may experience as result of cyclones may change. Populations of sea turtles may 
also shift their nesting sites to a more southerly beach to adapt to a rise in sea level or warmer sand temperatures (as suggested by Hays et al. 2001). In this case, the cyclonic disturbance in their new nesting grounds may be different, as sea turtle populations with more southerly nesting grounds have historically had and are predicted to have a higher frequency of cyclone hits in a year (see Fig. 2, Table 3).

As discussed above, determining the exact extent of future cyclonic disturbance to sea turtle populations is challenging, as there is still high uncertainty in future projections of cyclonic activity (e.g. Pittock et al. 2006, Walsh \& Pittock 1998) and sea turtles may slowly respond to future changes in climate and alter their nesting locations. Indeed, several studies have highlighted the uncertainties and variability regarding future cyclonic activities (e.g. Hughes 2003, Emanuel et al. 2008). Although predictions of cyclonic activity in a warming climate do vary, most studies predict an intensification of the strongest cyclones (Knutson et al. 1998, Walsh \& Ryan 2000, Oouchi et al. 2006, Kuleshov et al. 2008) and a decrease in the global frequency of cyclones (Bengtsson et al. 1996, 2007, Sugi et al. 2002, McDonald et al. 2005, Oouchi et al. 2006, Yoshimura et al. 2006, Vecchi \& Soden 2007, Zhao et al. 2009). Projected cyclonic intensification is likely to occur as a result of future increases in temperature and the amount of water vapor, both of which provide more energy for storms (Bengtsson et al. 2007). The projected decrease in cyclonic activity is due to a number of reasons, including an increase in the static stability and a reduction of tropical vertical atmospheric circulation, caused by large increases in atmospheric water vapor (Bengtsson et al. 2007) and regional increases in vertical wind shear (Vecchi \& Soden 2007).

Indeed, there was a great variability in the projected cyclone frequency between the simulations used in this study. For example, for the sGBR turtle population, 9 of the 11 simulations provide a relatively accurate representation of tropical cyclone activity affecting their nesting grounds. Of these 9 simulations, 2 project an increase in tropical cyclone frequency for 2055, 2 project a small decrease in cyclone frequency and 5 project large decreases in frequency of between 35 and $65 \%$. Thus, while the most likely projection is for a decrease in tropical cyclone frequency by 2055, the possibility of an increase for some nesting grounds needs to be considered in the development of future management plans for the studied turtle populations.

Nevertheless, as tropical cyclones can severely affect sea turtle nesting ecology (Milton et al. 1994, Godfrey et al. 1996, Martin 1996, Houghton et al. 2007, Pike \& Stiner 2007), it is important that studies continue to investigate the exposure and effects that sea turtle nesting grounds will experience in the future from cyclonic activity. However, as the distribution and frequency of cyclones is predicted to change, studies should move beyond investigating how intensification of cyclones will affect sea turtle populations, and, similar to this study, also explore how cyclonic frequency might change at key nesting grounds and how predicted changes may influence sea turtle population structure and demography. This will provide an understanding of whether future cyclonic activity will add additional stress to populations of sea turtles that are currently unaffected by cyclones.

Acknowledgements. We thank J. Nott, K. Wash and M. Puotinen for suggestions during the initial aspects of this work. We are also grateful for comments provided by M. Hamman, C. Limpus, J. Cinner, T. McClanahan and 3 anonymous reviewers. Special thanks go to J. Garcon for assistance in collecting information for the nesting seasonality and location for each population. Acknowledgements are extended to J. Katzfey, $M$. Thatcher and K. Nguyen for providing the ensemble of CCAM data sets used in this study. During manuscript preparation, M.M.P.B.F. was supported by an Australian Postgraduate Award.

\section{LITERATURE CITED}

Abbs DJB (2009) The impact of climate change on the climatology of tropical cyclones in the Australian region. CSIRO Marine and Atmospheric Research, Aspendale

Abbs DJ, Timbal B, Rafter AS, Walsh KJE (2007) Severe weather. In: Pearce KB, Holper PN, Hopkins M, Bouma WJ, Whetton PH, Hennessy KJ, Power SB (eds) Climate change in Australia. Technical report 2007. CSIRO Marine and Atmospheric Research, Aspendale, p 102-106

Ackerman RA (1997) The nest environment and the embryonic development of sea turtles. In: Lutz PL, Musick JA, Wyneken J (eds) The biology of sea turtles, Vol I. CRC Press, New York, NY, p 83-106

Baker JD, Littnan CL, Johnston DW (2006) Potential effects of sea level rise on the terrestrial habitats of endangered and endemic megafauna in the Northwestern Hawaiian Islands. Endang Species Res 2:21-30

Bengtsson LM, Botzet M, Esch M (1996) Will greenhouseinduced warming over the next 50 years lead to higher frequency and greater intensity of hurricanes? Tellus 48A: 57-73

Bengtsson LM, Hodges KI, Esch M, Keenlyside N, Kornbleuh L, Luo JJ, Yamagata T (2007) How may tropical cyclones change in a warmer climate? Tellus 59A:539-561

Carthy RR, Foley AM, Matsuzawa Y (2003) Incubation environment of loggerhead turtle nests: effects on hatching success and hatchling characteristics. In: Bolten AB, Witherington BE (eds) Loggerhead sea turtles. Smithsonian Books, Washington, DC, p 144-153

Chaloupka M, Bjorndal KA, Balazs GH, Bolten AB and others (2008) Encouraging outlook for recovery of a once severely exploited marine megaherbivore. Glob Ecol Biogeogr 17:297-304

> Davenport J (1997) Temperature and the life-history strategies of sea turtles. J Therm Biol 22:479-488

Dobbs KA, Miller JD, Limpus CJ, Landry AMJ (1999) Hawksbill turtle, Eretmochelys imbricata, nesting at Milman Island, northern Great Barrier Reef, Australia. Chelonian 
Conserv Biol 3:344-361

Emanuel K, Sundararajan R, Williams J (2008) Hurricanes and global warming: results from downscaling IPCC AR4 simulations. Bull Am Meteorol Soc 89:347-367

Fish MR, Cote IM, Gill JA, Jones AP, Renshoff S, Watkinson AR (2005) Predicting the impact of sea-level rise on Caribbean sea turtle nesting habitat. Conserv Biol 19:482-491

Fish MR, Cote IM, Horrocks JA, Mulligan B, Watkinson AR, Jones AP (2008) Construction setback regulations and sea-level rise: mitigating sea turtle nesting beach loss. Ocean Coast Manag 51:330-341

Fuentes MMPB, Hamann M, Lukoschek V (2009a) Marine reptiles and climate change in Australia. In: Poloczanska ES, Hobday AJ, Richardson AJ (eds) A marine climate change impacts and adaptation report card for Australia 2009. NCCARF Publication 05/09. National Climate Change Adaption Research Facility, Gold Coast, Qld. www.ocean climatechange.org.au/content/images/uploads/Marine Reptiles_FINAL.pdf

Fuentes MMPB, Maynard JA, Guinea M, Bell IP, Werdell PJ, Hamann M (2009b) Proxy indicators of sand temperature help project impacts of global warming on sea turtles in northern Australia. Endang Species Res 9:33-40

Fuentes MMPB, Limpus CJ, Hamann M (2010a) Vulnerability of sea turtle nesting grounds to climate change. Glob Change Biol doi:10.1111/j.1365-2486.2010.02192.x

Fuentes MMPB, Hamann M, Limpus CJ (2010b) Past, current and future thermal profiles for green turtle nesting grounds: implications from climate change. J Exp Mar Biol Ecol 383:56-64

Fuentes MMPB, Limpus CJ, Hamann M, Dawson J (2010c) Potential impacts of projected sea level rise to sea turtle rookeries. Aquat Conserv: Mar Freshw Ecosyst 20:132-139

Glen F, Mrosovsky N (2004) Antigua revisited: the impact of climate change on sand and nest temperatures at a hawksbill turtle (Eretmochelys imbricata) nesting beach. Glob Change Biol 10:2036-2045

Godfrey MH, Barreto R, Mrosovsky N (1996) Estimating past and present sex ratios of sea turtles in Suriname. Can J Zool 74:267-277

Harris ANM, Kwan D, Williams G (2000) Torres Strait turtles 2000, fishery assessment report. Torres Strait Fisheries Assessment Group. Australian Fisheries Management Authority, Canberra

Harvey T, Townsend S, Kenyon N, Redfern G (2005) Monitoring of nesting sea turtles in the Coringa Herald National Nature Reserve (1991/92 to 2003/04 nesting seasons). Australian Government Department of the Environment, Water, Heritage and the Arts (formerly Australian Government Department of Environment and Heritage), Canberra

Hawkes LA, Broderick AC, Godfrey MH, Godley BJ (2007) Investigating the potential impacts of climate change on a marine turtle population. Glob Change Biol 13:923-932

> Hawkes LA, Broderick AC, Godfrey MH, Godley BJ (2009) Climate change and marine turtles. Endang Species Res 7 : $137-154$

Hays GC, Godley BJ, Broderick AC (1999) Long-term thermal conditions on the nesting beaches of green turtles on Ascension Island. Mar Ecol Prog Ser 185:297-299

> Hays GC, Ashworth JS, Barnsley MJ, Broderick AC and others (2001) The importance of sand albedo for the thermal conditions on sea turtle nesting beaches. Oikos 93:87-94

> Hays GC, Broderick AC, Glen F, Godley BJ (2003) Climate change and sea turtles: a 150-year reconstruction of incubation temperatures at a major marine turtle rookery. Glob Change Biol 9:642-646
Holland GJ (1981) On the quality of the Australian tropical cyclone data base. Aust Meteorol Mag 29:169-181

Houghton JDR, Myers AE, Lloyd C, King RS, Isaacs C, Hays GC (2007) Protracted rainfall decreases temperature within leatherback turtle (Dermochelys coriacea) clutches in Grenada, West Indies: ecological implications for a species displaying temperature dependent sex determination. J Exp Mar Biol Ecol 345:71-77

Hughes L (2003) Climate change and Australia: trends, projections and impacts. Aust Ecol 28:423-443

IPCC (Intergovernmental Panel on Climate Change) (2007) Climate change 2007 - the physical science basis. Contribution of Working Group I to the Fourth Assessment Report of the IPCC. Cambridge University Press, Cambridge

Janzen FJ (1994) Climate change and temperature-dependent sex determination in reptiles. Proc Natl Acad Sci USA 91:7487-7490

Johannes RE, Macfarlane JW (1991) Traditional fishing on the Torres Strait Islands. CSIRO Division of Fisheries, Hobart, TAS

Knutson TR, Tuleya RE (2004) Impact of $\mathrm{CO}_{2}$-induced warming on simulated hurricane intensity and precipitation: sensitivity to the choice of climate model and convective parametrization. J Clim 17:3477-3494

Knutson TR, Tuleya RE, Kurihara Y (1998) Simulated increase of hurricane intensities in a $\mathrm{CO}_{2}$-warmed world. Science 279:1018-1021

Kuleshov Y, Qi L, Fawcett R, Jones D (2008) On tropical cyclone activity in the Southern Hemisphere: trends and the ENSO connection. Geophys Res Lett 35:L14S08. doi:10.1029/2007GL032983

> Leslie LM, Karoly DJ, Leplastrier M, Buckley BW (2007) Variability of tropical cyclones over the southwest Pacific Ocean using a high resolution climate model. Meteorol Atmos Phys 97:171-180

Limpus CJ (1971) The flatback turtle, Chelonia depressa, Garman, in southeast Queensland, Australia. Herpetologica $27: 431-446$

Limpus CJ, Miller JD (2000) Final report for Australian hawksbill turtle population dynamics project. Queensland Parks and Wildlife Service, Brisbane

Limpus CJ, Reed PC (1985) The loggerhead turtle, Caretta caretta, in Queensland (Australia): observations on interesting behavior. Aust Wildl Res 12:535-540

Limpus CJ, Couper PJ, Couper KLD (1993) Crab Island revisited: reassessment of the world's largest flatback turtle rookery after twelve years. Mem Queensl Mus 33:277-289

Limpus CJ, Miller J, Parmenter J, Limpus DJ (2003) The green turtle, Chelonia mydas, population of Raine Island and the northern Great Barrier Reef 1843-2001. Mem Queensl Mus 49:349-440

Lutcavage ME, Plotkin P, Witherington B, Lutz PL (2003) Human impacts on sea turtles survival. In: Lutz PL, Musick JA, Wyneken J (eds) The biology of sea turtles, Vol II. CRC Press, New York, NY, p 387-410

Martin RE (1996) Storm impacts on loggerhead turtle reproductive success. Mar Turtle Newsl 73:10-12

Matsuzawa Y, Sato K, Sakamoto W, Bjorndal KA (2002) Seasonal fluctuations in sand temperature: effects on the incubation period and mortality of loggerhead sea turtle (Caretta caretta) pre-emergent hatchlings in Minabe. Mar Biol 140:639-646

> Mazaris AD, Mastinos G, Pantis JD (2009) Evaluating the impacts of coastal squeeze on sea turtle nesting. Ocean Coast Manag 52:139-145

> McDonald RE, Bleaken DG, Cresswell DR, Pope VD, Senior CA (2005) Tropical storms: representation and diagnosis 
in climate models and the impacts of climate change. Clim Dyn 25:19-36

McGregor JL (2005) C-CAM: geometric aspects and dynamical formulation. CSIRO Marine and Atmospheric Research Tech Rep 70. www.cmar.csiro.au/e-print/open/mcgregor_ 2005a.pdf

McGregor JL, Dix MR (2008) An updated description of the conformal-cubic atmospheric model. In: Hamilton $\mathrm{K}$ Ohfuchi W (eds) High resolution simulation of the atmosphere and ocean. Springer, New York, NY, p 51-76

Miller JD, Limpus CJ (1981) Incubation period and sexual differentiation in the green turtle Chelonia mydas. In: Banks CB, Martin AA (eds) Proceedings of the Melbourne Herpetological Symposium. The Zoological Board of Victoria, Melbourne, p 66-73

Milton SL, Leone-Kabler S, Schulman AA, Lutz PL (1994) Effects of Hurricane Andrew on the sea turtle nesting beaches of South Florida. Bull Mar Sci 54:974-981

Moore JE, Wallace BP, Lewison RL, Zydelis R, Cox TM, Crowder LB (2009) A review of marine mammal, sea turtle and seabird bycatch in USA fisheries and the role of policy in shaping management. Mar Pol 33:435-451

Morreale SJ, Ruiz GJ, Spotila JR, Standora EA (1982) Temperature-dependent sex determination: current practices threaten conservation of sea turtles. Science 216: 1245-1247

Munday PL, Jones PJ, Pratchett MS, Williams AJ (2008) Climate change and the future for coral reef fishes. Fish Fish 9:261-285

Nguyen KC, Walsh KJE (2001) Interannual, decadal, and transient greenhouse simulation of tropical cyclone-like vortices in a regional climate model of the South Pacific. J Clim 14:3043-3054

Nicholls N (1984) Southern oscillation, sea surface temperature, and interannual fluctuations in Australian tropical cyclone activity. Int J Climatol 4:661-670

- Oouchi KJ, Yosimura J,Yosimura H, Mizuta R, Kusonoki S, Noda A (2006) Tropical cyclone climatology in a globalwarming climate as simulated in a $20 \mathrm{~km}$ mesh global atmospheric model: frequency and wind intensity analyses. J Meteorol Soc Jpn 84:259-276

Pike DA, Stiner JC (2007) Sea turtles species vary their susceptibility to tropical cyclones. Oecologia 153:471-478

Pike DA, Antworth RL, Stiner JC (2006) Earlier nesting contributes to shorter nesting seasons for the loggerhead seaturtle, Caretta caretta. J Herpetol 40:91-94

Pittock AB, Abbs D, Suppiah R, Jones R (2006) Climatic back-

Editorial responsibility: Tim McClanahan,

Mombasa, Kenya ground to past and future floods in Australia. In: Poliani A (ed) Floods in an arid climate. Adv Ecol Res 39:13-39

Poloczanska ES, Limpus CJ, Hays GC (2009) Vulnerability of marine turtles to climate change. In: Sims DW (ed) Advances in marine biology. Academic Press, Burlington, MA, p 151-211

Reed P (1980) The sex ratios of hatchling loggerhead turtles the progeny of two nesting adult females. BSc Honours thesis, James Cook University, Townsville, Qld

Spotila JR, Standora EA (1985) Environmental constraints on the thermal energetics of sea turtles. Copeia 1985: $694-702$

Sugi M, Noda A, Sato N (2002) Influence of the global warming on tropical cyclone climatology: an experiment with the JMA Global Model. J Meteorol Soc Jpn 80:249-272

Van Houtan KS, Bass OL (2007) Stormy oceans are associated with declines in sea turtle hatching. Curr Biol 17: R590-R591

Vecchi GA, Soden BJ (2007) Increased tropical Atlantic wind shear in model projections of global warming. Geophys Res Lett 34:L08702. doi:10.1029/2006GL028905

- Walsh KJE, Pittock AB (1998) Potential changes in tropical storms, hurricanes, and extreme rainfall events as a result of climate change. Clim Change 39:199-213

> Walsh KJE, Ryan BF (2000) Tropical cyclone intensity increase near Australia as a result of climate change. J Clim 13:3029-3036

Webster PJ, Holland GJ, Curry JA, Chang HR (2005) Changes in tropical cyclone number, duration, and intensity in a warming environment. Science 309:1844-1846

Weishampel JF, Bagley DA, Ehrhart LM (2004) Earlier nesting by loggerhead sea turtles following sea surface warming. Glob Change Biol 10:1424-1427

Witt MJ, Hawkes LA, Godfrey MH, Godley BJ, Broderick AC (2010) Predicting the impacts of climate change on a globally distributed species: the case of the loggerhead turtle. J Exp Biol 213:901-911

Yntema CL, Mrosovsky N (1980) Sexual differentiation in hatchling loggerheads (Caretta caretta) incubated at different controlled temperatures. Herpetologica 36:33-36

> Yoshimura J, Masato S, Noda A (2006) Influence of greenhouse warming on tropical cyclone frequency. J Meteorol Soc Jpn 84:405-428

Zhao M, Held I, Lin SJ, Vecchi G (2009) Simulations of global hurricane climatology, interannual variability, and response to global warming using a $50 \mathrm{~km}$ resolution GCM. J Clim 22:6653-6678

Submitted: March 3, 2010; Accepted: May 26, 2010

Proofs received from author(s): July 27, 2010 